\title{
Study on the Relationship between Air Pollution and Stroke
}

\author{
Chunshan $\mathrm{ZHAO}^{1, \mathrm{a}}$, Chunguo $\mathrm{LI}^{2, \mathrm{~b}}$ \\ ${ }^{1}$ College of Nursing, Beihua University, Jilin, 132013, China \\ 2Jilin City Central Hospital, Jilin, 132011, China \\ Corresponding author: Chunguo LI \\ aemail:forchunshan@163.com, bemail:xinfeifusu@163.com
}

\begin{abstract}
Keywords: heating period; air pollution; stroke; health.
Abstract.Purpose: To research the relationship between air pollution and the incidence of stroke in Jilin. Methods: a random sampling method was used to select 370 patients with new stroke who were treated in Jilin Central Hospital and Beihua University Affiliated Hospital from October 2016 to March 2017. Pearson correlation analysis was used for statistical analysis of the data. Results: The incidence of stroke was related to $\mathrm{PM}_{10}, \mathrm{PM}_{2.5}, \mathrm{SO}_{2}, \mathrm{NO}_{2}$ and other air fine particles. Conclusion: Air pollution in Jilin is serious in winter, and there is a direct relationship between the air pollution and the incidence of stroke.
\end{abstract}

\section{Introduction}

With the accelerating industrialization and the expansion of city scale, air pollution has been rising in cities. Environmental risks caused by air pollution have become environmental problems that seriously harm human health. More and more evidence shows that air pollution is a potential risk factor for stroke, and it is a risk factor for increasing stroke. It is related to the onset and death of stroke ${ }^{[1-2]}$. Stroke can also be called cerebrovascular accident. It is mainly divided into two types: hemorrhagic stroke and ischemic stroke, the latter is the most common stroke. It is currently one of the three leading causes of death from human diseases, and also the main cause of disability. 50\% $70 \%$ of survivors have severe disabilities such as deafness and aphasia, which places a heavy burden on individuals, families, and society. Jilin is a cold place and has a long heating period when comes to winter. So, the most serious air pollution happened in winter. This study investigated the relationship between air pollution and stroke in the region, and clarified the relationship between the two, providing a reference for the prevention of stroke in the future.

\section{Objects and methods}

\section{Objects}

Using random sampling to select 370 patients with new stroke who were treated in Jilin Central Hospital and Beihua University Affiliated Hospital from October 2016 to March 2017. After excluding unqualified patients, the final number of selected subjects was 370 , among which there are 213 males and 157 females, aged $61.15 \pm 8.30$ years.

\section{Data sources}

The air pollution index comes from the air quality real-time release system of the Jilin City Environmental Protection Bureau, with a total of 7 monitoring points. The real-time releasing website updates once every hour. This study selects 2 days a week, and the daily data released at 9:00 was chosen as the daily average value of this monitoring point.

Statistical Analysis

SPSS19.0 statistical software was used for analysis. 


\section{Results}

\section{The incidence of stroke in the heating period.}

This study investigated the incidence of stroke monthly during the heating period, and the incidence rate was higher in January, February and December, as shown in table 1.

Table 1 The incidence of stroke in the heating period

\begin{tabular}{lcc}
\hline month & stroke cases & proportion \\
\hline 1 & 68 & 18.2 \\
2 & 66 & 17.9 \\
3 & 62 & 16.8 \\
10 & 49 & 13.2 \\
11 & 59 & 16.1 \\
12 & 66 & 17.8 \\
\hline
\end{tabular}

The relationship between the incidence of stroke and air pollution.

Analysis the index of air pollution and stroke incidence with Pearson Correlation, the results shows that the incidence of stroke was positively correlated with $\mathrm{PM}_{10}, \mathrm{PM}_{2.5}, \mathrm{SO}_{2}$, and $\mathrm{NO}_{2}$, as shown in Table 2.

Table 2 The relationship between the incidence of stroke and air pollution

\begin{tabular}{lllll}
\hline & $\mathrm{PM}_{2.5}$ & $\mathrm{SO}_{2}$ & $\mathrm{NO}_{2}$ & $\mathrm{PM}_{10}$ \\
\hline stroke & $0.250 * *$ & $0.193 *$ & $0.211 * *$ & $0.310 * *$ \\
\hline Note: $* * \mathrm{P}<0.01$, & $* \mathrm{P}<0.05$ & & &
\end{tabular}

\section{Discussion}

Air pollution is classified into gaseous pollution and particulate pollution according to the form. The gaseous pollutants are represented by sulfur dioxide $\left(\mathrm{SO}_{2}\right)$, nitrogen dioxide $\left(\mathrm{NO}_{2}\right)$, carbon monoxide $(\mathrm{CO})$, and ozone $\left(\mathrm{O}_{3}\right)$, etc. Particulate pollutants are mixtures(Particulate Matter, PM)of solid and liquid particles suspended in the atmosphere. Which are invisible to the naked eye and are called haze in meteorology.

Effects of air pollutants on cerebral vascular mechanisms.

Epidemiological investigations have confirmed that $\mathrm{PM}_{2.5}$ is closely related to the occurrence and development of cerebrovascular disease. The mechanism of cerebrovascular damage may be related to the following factors: (1) $\mathrm{PM}_{2.5}$ has a higher level of $\mathrm{PAH}$, which can lead to systemic inflammatory reactions and oxidative stress, and systemic inflammatory responses lead to damage of the vascular endothelium ${ }^{[3]}$. (2) $\mathrm{PM}_{2.5}$ can increase the amount of soluble intercellular adhesion molecule-1, soluble vascular cell adhesion molecule-1, endothelin and metalloproteinase- $9{ }^{[4]}$, which can mediate endothelial injury or lead to the formation of atherosclerosis, leading to the occurrence of cardiovascular and cerebrovascular events. (3) $\mathrm{PM}_{2.5}$ can also inhibit the expression of tissue factor pathway inhibitors and prevent the activation of anticoagulation mechanism in vivo through lowing the thrombomodulin, leading to the disorder of coagulation and fibrinolysis system and inducing thrombosis ${ }^{[5]}$.

\section{The relationship between air pollution and stroke.}

A large number of studies have shown that air pollution is closely related to the occurrence and death of cerebrovascular disease. Air pollution is associated with cardiovascular and cerebrovascular diseases not only in serious air pollution incidents, but also in mild air pollution areas ${ }^{[6]}$. The main pollutants in the atmosphere are $\mathrm{SO}_{2}, \mathrm{NO}_{2}, \mathrm{PM}_{10}$ and $\mathrm{PM}_{2.5}$, which are closely related to the health of people. Studies at home and abroad show that PM10 caused 60,000 deaths in the United States and 
10,000 deaths in the United Kingdom each year. Even short-term exposure to $\mathrm{PM}_{2.5}$ for several hours can cause stroke or even death ${ }^{[7-8]}$. Zhang Yanping and others' studies have shown that atmospheric $\mathrm{PM}_{10}$ pollution in Taiyuan City has an acute impact on the mortality of residents of cardiovascular and cerebrovascular diseases, and the relative risk of $\mathrm{PM}_{10}$ on cardiovascular and cerebrovascular disease mortality is greater than that of $\mathrm{SO}_{2}$, the relative risk of $\mathrm{SO}_{2}$ and $\mathrm{NO}_{2}$ on health is less than $\mathrm{PM}_{10}{ }^{[9]}$. Surveys in Fushun District also show that atmospheric pollution is associated with increased mortality from cardiovascular and cerebrovascular diseases ${ }^{[10]}$. There is no report on the relationship between the incidence of stroke and air pollution in Guangzhou. This study shows that the number of stroke patients in Jilin is positively correlated with $\mathrm{PM}_{10}, \mathrm{NO}_{2}$, and $\mathrm{SO}_{2}(\mathrm{P}<0.05)$, which is consistent with some studies at home and abroad ${ }^{[11]}$.

\section{Conclusions}

In conclusion, exposure to high concentrations of air pollution increases the risk of stroke and death. Both long-term and short-term air pollution can significantly increase the risk of ischemic stroke and death. These results are of great value in environmental studies and also provide a scientific basis for the prevention of stroke.

\section{Acknowledgements}

This work was financially supported by the Jilin provincial science and Technology Department Project (20130624003JC), Jilin science and Technology Bureau project (201737167) and Beihua University doctoral foundation project (20180416).

\section{References}

[1]Maheswaran R. Air pollution and stroke an overview of the evidence base[J].Spat Spatiotemporal Epidemiol,2016,18: 74-81.

[2]Chung JW, Bang OY, Ahn K, et al. Air pollution is associated with ischemic stroke via cardiogenic embolism[J]. Stroke, 2017, 48(1):17-23.

[3]Bo L, Jiang S, Xie Y, et al. Effect of vitamin E and omega-3 fatty acids on protecting ambient PM2.5-induced inflammatory response and oxidative stress in vascular endothelial cells[J]. PLoS One,2016, 11(3): e152216.

[4]Rui W, Guan L, Zhang F, et al. PM2.5-induced oxidative stress increases adhesion molecules expression in human endothelial cells through the ERK/AKT/NF-KB-dependent pathway[J]. J Appl Toxicol, 2016,36(1):48-59.

[5]Hajat A, Allison M, Diez-Roux AV, et al. Long-term exposure to air pollution and markers of inflammation, coagulation, and endothelial activation[J]. Epidemiology, 2015, 26(3): 310-320.

[6]Samet JM, Dominici F, Zeger SL, et al. National morbidity, mortality and air pollution study, partI: methods and methodologic issues[J]. Health Effects Inst Rep, 2000; 94: 15-74

[7] KA , Beru Be . Elect ron microscopy of urban airborne particulatemat- ter [J] . Microscopy and Analysis ,1997; (Sep) :11-13

[8]Brook RD.Is air pollution a cause of cardiovascular disease? Updated review and controversies[J]. Rev Environ Health. 2007 ,Apr-Jun;22(2):115-37

[9]Zhang Yanping, Zhang Zhiqin, Zhang Xiaoping et al. Generalized additive model analysis on the acute effect of Air pollution in Taiyuan on mortality of cardiovascular and cerebrovascular diseases[J].. Environment and Health,2008; 25(1): 11-15 
[10]Du Yingjie, Lin Gang et al. Quantitative analysis of airborne particulate pollution and the mortality of cardiovascular disease in Fushun city $[\mathrm{J}]$. Environment and Health, 2006; (6) : 493-496

[11] Villeneuve PJ, Chen L, Stieb D, Rowe BH.Associations between outdoor air pollution and emergency department visits for stroke in Edmonton[J]., Canada. Eur $\mathrm{J}$ Epidemiol. 2006;21(9):689-700 